\title{
Brain docosahexaenoic acid (DHA) levels of young rats are related to alpha-linolenic acid (ALA) levels and fat matrix of the diet: impact of dairy fat ${ }^{*}$
}

\author{
Bernadette DELPLANQUE ${ }^{1}$ \\ Qin $\mathrm{DU}^{2,4}$ \\ Pascale LERUYET ${ }^{3}$ \\ Genevieve AGNANI \\ Nicole PAGES ${ }^{1}$ \\ Daniel GRIPOIS ${ }^{1}$ \\ Hassina OULD-HAMOUDA ${ }^{1}$ \\ Pierre CARAYON ${ }^{4}$ \\ Jean-Charles MARTIN ${ }^{2}$ \\ ${ }^{1}$ UMR 8195 CNPS « Centre de \\ Neurosciences Paris-Sud", \\ NMPA « Neuroendocrinologie \\ Moléculaire de la Prise Alimentaire", \\ Université Paris-Sud XI, \\ Orsay, \\ F- 91405 France \\ $<$ bernadette.delplanque@u-psud.fr> \\ 2 UMR1260, \\ Plateau BioMeT, \\ Marseille, \\ F-13385 France; \\ Univ Aix-Marseille, \\ Faculté de Médecine Timone, \\ Marseille, \\ F-13385 France \\ ${ }^{3}$ LACTALIS, \\ $R \& D$, \\ Retiers, \\ F-35240 France \\ ${ }^{4}$ Hopital de La Timone, \\ Service of Biochemistry and Molecular \\ Biology, \\ Marseille, \\ F-13005 France
}

\footnotetext{
"Lecture from the symposium "Lipids and Brain II" held by The French Society for the Study of Lipids (Sfel) - Paris 28-30 March 2011, cf. OCL 18-4 and 18-5.
}

\begin{abstract}
Dososahexaenoate (DHA) is highly concentrated in mammalian nervous and visual systems and its deficiency during gestation, lactation and early life, could have dramatic impacts on brain functions and mental health. Achieving an appropriate DHA status in the neonatal brain is an important goal of neonatal nutrition. We evaluated how $\alpha$-linolenic acid (ALA) provided by different dietary fat matrices improved DHA content in the brains of both young male and female rats. Young rats born from dams fed during gestation and lactation with a low ALA diet ( $0.4 \%$ of fatty acids) were subjected for 6 weeks after weaning to an anhydrous dairy fat blend-based diet that provided 1.5\% ALA or to a palm oil blend-based diet that provided the same ALA level: either 1.5\% ALA or $1.5 \%$ ALA and $0.12 \%$ DHA with $0.4 \%$ arachidonic acid (ARA). With each diet the $n-6 /$ $n$-3 ratio was similar (10) to follow the values generally recommended for infant formula. Fatty acids analysis in whole brain showed that $1.5 \%$ ALA dairy fat blend was superior to both $1.5 \%$ ALA palm-oil blends, supplemented or not with dietary DHA, for increasing brain DHA. Females compared to males had significantly higher brain DHA with the $1.5 \%$ ALA palm-blend diet, but the dietary supplementation with DHA smoothed the differences by a specific increase of males DHA brain. In conclusion, dairy fat blend enriched with ALA appear to be an interesting strategy for achieving optimal DHA levels in the brain of post-weaning rats. Inclusion of dairy fat in infant formulas should be reconsidered.
\end{abstract}

Key words: dairy fat, palm oil, $\alpha$-linolenic acid, brain, docosahexaenoic acid, rat neonates

Docosahexaenoic acid (DHA;22:6n-3)
and arachidonic acid (AA;20:4n-6) are
highly concentrated in mammalian
nervous and visual systems (Innis,
2007). There is an increased demand
forn-3 long-chain polyunsaturated fatty
acids (LC-PUFA), particularly DHA, to
support optimal visual and cognitive
development in infants during fetal life
and newborn nursing (Simopoulos,
1991; Innis et al., 2001; Hoffman et
al., 2000). Linoleic acid (LA; $18: 2 n-6)$
and alpha-linolenic acid (ALA; $18: 3 n-3$ )
are the precursors of long-chain n-6
and n-3 fatty acids, respectively. Al-
though they can be synthesized from
their respective precursor fatty acids
(Mohrhauer and Holman, 1963), and, although it has been shown in rats that supplementation of mothers with ALA or DHA leads to the same LC-PUFA accretion in maternal, fetal and newborn brains (Valenzuela et al., 2004; Childs et al., 2010b; Childs et al., 2011), synthesis (especially DHA synthesis) could be insufficient to cover growth needs (Poumes-Ballihaut et al., 2001; Bowen and Clandinin, 2005; Plourde and Cunnane, 2007). Therefore, it may be necessary to increase the dietary intake of DHA and/or increase the synthetic capacity for metabolizing ALA to DHA in mothers and newborns (Guesnet and Alessandri, 2010).

Infant formulas were gradually replacing mother's milk for more than 50

To cite this article: Delplanque B, Du Q, Leruyet P, Agnani G, Pages N, Gripois D, ould-Hamouda H, Carayon P, Martin JC. Brain docosahexaenoic acid (DHA) levels of young rats are related to alpha-linolenic acid (ALA) levels and fat matrix of the diet: impact of dairy fat. OCL 2011; 18(6): 293-296. doi : 10.1684/ocl.2011.0420 
years and, at least in Europe are usually prepared with vegetable oils. The compositions of these formulas are controlled in terms of fat for most fatty acids and especially essential fatty acids (European Economical Community rules, 2008; Alessandri et al., 1996). Furthermore, in an attempt to mimic the composition of mother's milk, long chains n-3 and n-6 fatty acids (DHA and ARA) could be added (Alessandri et al., 1996; Guesnet and Alessandri, 2010).

Throughout the ages, infant formulas have been prepared with dairy fat, which, to some extent, is less different from breast milk for some components that are not present in vegetable fat formulas (i.e., cholesterol and shortchain FA) (Radbill, 1981). For example, the short- or medium-chain fatty acids in milk fat are more efficiently absorbed and might be beneficial for health (Bach and Babayan, 1982). Some studies reported the beneficial impact of dairy products on the bioconversion of ALA in humans or animal studies (Dabadie et al., 2005; Rioux et al., 2011; Legrand et al., 2010). However, the use of dairy fat for infant formulas is still a matter of debate in various countries (Stevens et al., 2009).

Breast feeding is promoted all over the world as the gold standard, at least for the two to six first months. However the quality of Infant formulas for the following months is still important, and the use of dairy fat during this period could be of interest.

In an attempt to validate the potential replacement of vegetable fats with dairy fat in infant formulas, we used the rat as a nutritional model, since many studies aiming determinating of the needs of the human brain are based on this model since more than 30 years. This animal was used in our study to compare the effects on brain fatty acids (specifically DHA) of dietary blends based on dairy fat instead of palm oil, which provide the same quantities of essential fatty acids. The levels of ALA and LA in these experimental diets followed the recommended and commonly used values in most commercial vegetable fat formulas. For this purpose, sunflower and rapeseed oils were added to maintain the levels of ALA (1.5\%) and LA (16\%) and the $n-6 / n-3$ ratio within the recommended values of 9 to 10 .

Because human milk contains DHA (0.2$0.4 \%)$ and ARA (0.4-0.8\%), it has been proposed that formulas that replace breast-feeding should be supplemented with these long-chain n-3 fatty acids (Guesnet and Alessandri, 2010). Therefore, we also compared the previous dairy and palm blends to a classical ALAenriched (1.5\%) palm blend enriched with DHA and ARA levels similar to those used in infant formulas $(0.12 \%$ and $0.40 \%$ of fatty acids).

In the present work, we compared the effects of ALA enriched dairy-fat-blend and palm-ALA regular blends (with or without supplementation with longchain $n-3$ ) on the restoration of the fatty acid profiles of brains from ALAdeficient post-weaning rats.

For this purpose we used a model of rat brain restoration of $n-3$ fatty acids by using different blends of lipids in the first generation of post-weaning rats (males and females) deficient in $n-3$, born from
ALA-poor dams (Du et al., 2011). ALA deficiency over both gestation and lactation in the dams was achieved by feeding a palm-oil-blend-based diet $(0.4 \% \mathrm{ALA})$, and the rat pups were then switched at weaning to either a palm-oil-blend diet or to a dairy-fat diet supplemented with sunflower and rapeseed oils to maintain 16\% LA and 1.5\% ALA for 6 weeks (table 1).

We evaluated:

The impact on brain DHA of a dietary Dairy fat matrix versus a Palm matrix having the same level of ALA (1.5\%) (figure 1).

The $1.5 \%$ ALA dairy fat blend induced similar levels of brain DHA of young rats, irrespective of the gender, and were significantly higher to the brain DHA of the young rats on the $1.5 \%$ ALA Palm matrix. Moreover, contrarily to the dairy fat diet, the palm matrix induced a gender difference, with male rats showing lower levels of Brain.

The impact on brain DHA of a dietary Dairy fat blend (1.5\% ALA) versus a Palm blend (1.5\% ALA) supplemented with Dietary preformed DHA (0.12\%) (figure 1).

Another diet was tested: 1.5\%-ALA palm diet supplemented with $0.12 \%$ DHA and $0.4 \%$ ARA, to mimic the LC PUFA supplemented formula and was compared to 1.5\% ALA-palm-blend and to $1.5 \%$ ALA-dairy-fat blend, non-supplemented with LCn-3.

The supplementation with dietary preformed DHA to the palm oil based diet increased the DHA levels in male brains only, and allowed the restoration of

Table 1. Fatty acid composition of the diets. Palm, Palm + DHA and dairy fat were blended with rapeseed and sunflower oils to maintain an ALA level of $1.5 \%$ of total fat.

\begin{tabular}{|lccr|}
\hline FA & Palm ALA 1,5\% & Palm ALA 1,5\% + DHA & Dairy fat ALA 1,5\% \\
\hline Myristic & 0,82 & 0,82 & 7,48 \\
\hline Palmitic & 36,15 & 36,15 & 19,85 \\
\hline Stearic & 4,12 & 4,12 & 9,64 \\
\hline Oleic & 38,44 & 38,44 & 26,62 \\
\hline $\mathbf{1 8 : 2 n - 6}$ & $\mathbf{1 5 , 9 8}$ & $\mathbf{1 5 , 9 8}$ & $\mathbf{1 3 , 8 8}$ \\
\hline $\mathbf{1 8 : 3 n - 3}$ & $\mathbf{1 , 5 6}$ & $\mathbf{1 , 5 6}$ & $\mathbf{1 , 5 3}$ \\
\hline n-6/n-3 & 10,27 & 10,27 & 9,09 \\
\hline SFA & 42 & 42 & 41 \\
\hline DHA added & 0 & 0,12 & 0 \\
\hline Short and medium chains & 0 & 0 & $\mathbf{6 , 1 3}$ \\
\hline
\end{tabular}




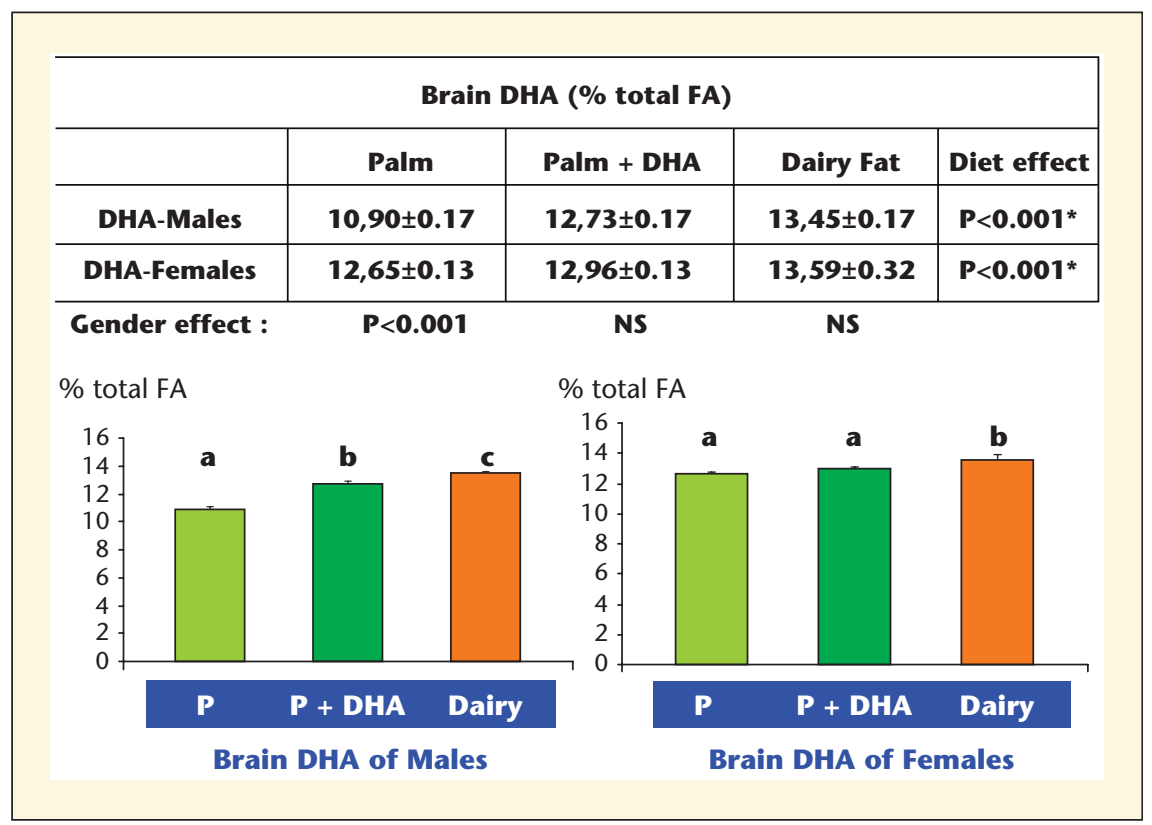

Figure 1. Brain DHA levels in young male and female rats receiving different diets for 6 weeks post weaning: Palm $(P)$ and Palm+DHA $(P+D H A)$ and Dairy fat were blended with rapeseed and sunflower oils to maintain an ALA level of $1.5 \%$ of total fat. A,b,c significantly different $p<0.001$.

their brain DHA content to the values found in females brains fed the same $1.5 \%$ ALA palm diet.

In males and females rats fed with $1.5 \%$ ALA dairy fat, the levels of brain DHA were similar and significantly higher than the corresponding levels obtained with the $1.5 \%$ ALA Palm matrix supplemented or not with preformed DHA.

\section{Discussion}

The main finding of our study is that an anhydrous dairy-fat-based diet with $1.5 \%$ ALA is more efficient than a palm oil blend providing the same ALA level and $0.12 \%$ added DHA and $0.4 \%$ ARA for increasing brain DHA levels in postweaning rats. Together, these observations clearly demonstrated that brain DHA levels can be improved by dairy fat based-diets.

We were unable to show that the various diets cause any selective desaturase and elongase gene activation (Du et al., 2011; Tu et al., 2010). Thus, the substrate quantity and quality impact is probably the mechanism driving the desaturation pathways toward very LCPUFA tissue accretion as observed by others. In that respect, the dairy fats differed from the plant oils in their palm-oil-based diets. The brain DHA levels were lower in males than in females in palm-oil-based diet but comparable in males and females in the counterpart diet that provided preformed DHA.

In conclusion, our study shows that a dairy fat blend providing the recommended values of essential fatty acids ( $1.5 \%$ ALA) with a LA/ALA ratio of 10 is superior to the plant oil blend even when the recommended DHA levels are exogenously provided. A gender effect with regard to brain DHA (lower in males) is linked specifically to the dietary conditions of the vegetable formula with the recommended $1.5 \%$ levels of ALA, which could be overcome by the DHA supplementation. Dairy fat should be reevaluated for infant formulas.

\section{REFERENCES}

Alessandri JM, Goustard B, Guesnet P, Durand $G$. Polyunsaturated fatty acids status in blood, heart, liver, intestine, retina and brain of newborn piglets fed either sow milk or a milk replacer diet. Reprod Nutr Dev 1996; 36: 95-109.

Bach AC, Babayan VK Medium-chain triglycerides: an update. Am J Clin Nutr 1982; 36: 950-62.

Bendixen $\mathrm{H}$, Flint A, Raben A, et al. Effect of 3 modified fats and a conventional fat on appetite, energy intake, energy expenditure, and substrate oxidation in healthy men. $\mathrm{Am}$ J Clin Nutr 2002; 75: 47-56.

Bowen RA, Clandinin MT. Maternal dietary 22: $6 n-3$ is more effective than $18: 3 n-3$ in increasing the 22: $6 \mathrm{n}-3$ content in phospholipids of glial cells from neonatal rat brain. $\mathrm{Br}$ J Nutr 2005; 93: 601-11.

Childs CE, Romeu-Nadal M, Burdge GC, Calder PC. Gender differences in the n-3 fatty acid content of tissues. Proc Nutr Soc 2008; 67: 19-27.

Childs CE, Romeu-Nadal M, Burdge GC, Calder PC. The polyunsaturated fatty acid, composition of hepatic and plasma lipids differ by both sex and dietary fat intake in rats. I Nutr 2010a; 140: 245-50.

Childs CE, Romijn T, Enke U, Hoile S, Calder PC. Maternal diet during pregnancy has tissue-specific effects upon fetal fatty acid composition and alters fetal immune parameters. Prostaglandins Leukot Essent Fatty Acids 2010b; 83: 179-84.

Childs CE, Fear AL, Hoile SP, Calder PC. Different dietary omega-3 sources during pregnancy and DHA in the developing rat brain. OCL 2011; 18: 259-62. 
Dabadie H, Peuchant E, Bernard M, LeRuyet $P$, Mendy F. Moderate intake of myristic acid in sn-2 position has beneficial lipidic effects and enhances DHA of cholesteryl esters in an interventional study. I Nutr Biochem 2005; 16: 375-82.

Extier $\mathrm{A}$, Langelier $\mathrm{B}$, Perruchot $\mathrm{MH}$, et al. Gender affects liver desaturase expression in a rat model of n-3 fatty acid repletion. J Nutr Biochem 2010; 21: 180-7.

Directive. 2006/141/CE de la commission, du 22 décembre 2006 concernant les préparations pour nourrissons et les préparations de suite et modifiant la directive 1999/ 21/CE, Règlement (CE) $n^{\circ} 1243 / 2008$ de la commission du 12 décembre 2008.

Guesnet P, Alessandri JM. Docosahexaenoic acid (DHA) and the developing central nervous system (CNS) - Implications for dietary recommendations. Biochimie 2011; 93: $7-12$

Hoffman DR, Birch EE, Birch DG, et al. Impact of early dietary intake and blood lipid composition of long-chain polyunsaturated fatty acids on later visual development. I Pediatr Gastroenterol Nutr 2000; 31: 540-53.

Innis SM, Gilley J, Werker J. Are human milk long-chain polyunsaturated fatty acids related to visual and neural development in breast-fed term infants? / Pediatr 2001; 139: 532-8.
Innis SM. Dietary (n-3) fatty acids and brain development. / Nutr 2007; 137: 855-9.

Jones PJ. Dietary linoleic, alpha-linolenic and oleic acids are oxidized at similar rates in rats fed a diet containing these acids in equal proportions. Lipids 1994; 29: 491-5.

Legrand $P$, Beauchamp E, Catheline D, Pedrono F, Rioux V: Short chain saturated fatty acids decrease circulating cholesterol and increase tissue PUFA content in the rat. Lipids 2010; 45: 975-86.

Mohrhauer H, Holman RT. The Effect of Dose Level of Essential Fatty Acids Upon Fatty Acid Composition of the Rat Liver. J Lipid Res 1963; 4: 151-9.

Plourde M, Cunnane SC. Extremely limited synthesis of long chain polyunsaturates in adults: implications for their dietary essentiality and use as supplements. Appl Physiol Nutr Metab 2007; 32: 619-34.

Poumes-Ballihaut C, Langelier B, Houlier F, et al. Comparative bioavailability of dietary alpha-linolenic and docosahexaenoic acids in the growing rat. Lipids 2001; 36: 793-800.

Qin Du, Jean-Charles Martin, Genevieve Agnani, et al. Dairy fat blends high in $\alpha$ linolenic acid are superior to n-3 fatty acidenriched palm oil blends for increasing DHA levels in the brains of young rats. J Nutr Biochem accepted 2011.
Radbill S, Infant feeding through the ages. Clinical Pediatrics 1981; 10: 613-21.

Rioux V, Pédrono F, Legrand P. Regulation of mammalian desaturases by myristic acid: $\mathrm{N}$ terminal myristoylation and other modulations. Biochim Biophys Acta 2011; 1811: 1-8.

Rolland V, Roseau S, Fromentin G, Nicolaidis $S$, Tome D, Even PC. Body weight, body composition, and energy metabolism in lean and obese Zucker rats fed soybean oil or butter. Am J Clin Nutr 2002; 75: 21-30.

Simopoulos AP. Omega-3 fatty acids in health and disease and in growth and development. Am / Clin Nutr 1991; 54: 438-63.

Stevens EE, Patrick TE, Pickler R. A history of infant feeding. J Perinat Educ 2009 Spring; 18:32-39.

Tu WC, Cook-Johnson RJ, James MJ, Muhlhausler BS, Gibson RA. Omega-3 long chain fatty acid synthesis is regulated more by substrate levels than gene expression. Prostaglandins Leukot Essent Fatty Acids 2010; 83: 61-8.

Valenzuela A, Von Bernhardi R, Valenzuela V, et al. Supplementation of female rats with alpha-linolenic acid or docosahexaenoic acid leads to the same omega-6/omega-3 LCPUFA accretion in mother tissues and in fetal and newborn brains. Ann Nutr Metab 2004; 48: $28-35$. 